\title{
PESQUISA EM EDUCAÇÃO: DESAFIOS TEÓRICO- METODOLÓGICOS E CONTRIBUIÇÕES DA PERSPECTIVA BAKHTINIANA
}

\author{
Maria Nilceia Andrade Vieira ${ }^{1}$ \\ Valdete $\mathrm{Côco}^{2}$ \\ Silvana Ventorim ${ }^{3}$
}

\begin{abstract}
Resumo
Este artigo aborda as contribuições da perspectiva teórico-metodológica bakhtiniana (BAKHTIN, 2009; 2010; 2011; 2013) no desenvolvimento de pesquisas no campo educacional, destacando o percurso de uma pesquisa que tematiza a interlocução entre a avaliação institucional e a formação continuada na Educação Infantil. Pautando-se nas concepções de responsividade, excedente de visão, alteridade e relações dialógicas, o texto focaliza os princípios éticos articulados ao delineamento dos procedimentos metodológicos e à interação com os sujeitos participantes. As discussões apresentadas evidenciam que o aporte bakhtiniano, além de apoiar a trajetória desse processo investigativo em direção aos seus objetivos, constituiu-se como suporte formativo para as próprias questões metodológicas e seus entrelaçamentos com os diferentes movimentos da pesquisa.
\end{abstract}

Palavras-chave: Metodologia; Pesquisa em educação; Ética

\footnotetext{
${ }^{1}$ Doutoranda em Educação pelo Programa de Pós-graduação em Educação do Centro de Educação da Universidade Federal do Espírito Santo; integrante do Grupo de Pesquisa Formação e Atuação de Educadores - GRUFAE; Professora da Faculdade Estácio de Vila Velha. E-mail: nilceia_vilavelha@ hotmail.com

${ }^{2}$ Doutora em Educação pela Universidade Federal Fluminense; Professora vinculada ao Departamento de Linguagens, Cultura e Educação e ao Programa de Pós-graduação em Educação do Centro de Educação da Universidade Federal do Espírito Santo. E-mail: valdetecoco@ hotmail.com

${ }^{3}$ Doutora em Educação pela Universidade Federal de Minas Gerais. Professora do Departamento de Linguagens, Cultura e Educação e do Programa de Pós-Graduação em Educação do Centro de Educação da Universidade Federal do Espírito Santo. E-mail: silventorim@hotmail.com
} 


\title{
RESEARCH IN EDUCATION: THEORETICAL-METHODOLOGICAL CHALLENGES AND CONTRIBUTIONS FROM THE BAKHTINIAN PERSPECTIVE
}

\begin{abstract}
This article deals with the contributions of the Bakhtinian theoretical-methodological perspective (BAKHTIN, 2009; 2010; 2011; 2013) in the development of research in the educational field, highlighting the course of a research that thematizes the interlocution between the institutional evaluation and the continuing education in Education Child. Based on the conceptions of responsiveness, surplus of vision, alterity and dialogical relations, the text focuses on the ethical principles articulated to the delineation of methodological procedures and the interaction with the participating subjects. The discussions presented evidence that the Bakhtinian contribution, besides supporting the trajectory of this investigative process towards its objectives, was constituted as formative support for the own methodological questions and their interlacings with the different movements of the research.
\end{abstract}

Keywords: Methodology; Research in education; Ethic

\section{INVESTIGACIÓN EN EDUCACIÓN: DESAFÍOS TEÓRICO- METODOLÓGICOS Y CONTRIBUCIONES DE LA PERSPECTIVA BAKHTINIANA}

\section{Resumen}

Este artículo aborda las contribuciones de la perspectiva teórico-metodológica bakhtiniana (BAKHTIN, 2009; 2010; 2011; 2013) en el desarrollo de investigaciones en el campo educativo, destacando el recorrido de una investigación que tematiza la interlocución entre la evaluación institucional y la formación continuada en la Educación Infantil. El texto se centra en los principios éticos articulados al delineamiento de los procedimientos metodológicos ya la interacción con los sujetos participantes, en la concepción de responsividad, excedente de 
visión, alteridad y relaciones dialógicas. Las discusiones presentadas evidencian que el aporte bakhtiniano, además de apoyar la trayectoria de este proceso investigativo hacia sus objetivos, se constituyó como soporte formativo para las propias cuestiones metodológicas y sus entrelazamientos con los diferentes movimientos de la investigación.

Palabras clave: Metodología; La investigación en educación; Ética

\section{INTRODUÇÃO}

Considerando que o processo de assimilação da cultura humana se constitui como resposta às palavras do outro, compreendemos ${ }^{4}$ que desenvolver pesquisa em ciências humanas e, particularmente em educação, implica contato direto com os enunciados dos sujeitos, em suas distintas formas de expressão (BAKHTIN, 2011), numa ação que não é neutra nem imparcial e requer constantemente que façamos escolhas mediante nossa perspectiva ontológica e nossa forma de perceber o mundo (CHAUÍ, 2000).

Inseridos nessa dinâmica e instados pela proposta do dossiê de mover reflexões em torno de perspectivas teórico-metodológicas acerca da pesquisa em educação, buscamos, neste texto, em diálogo com referenciais bakhtinianos, compartilhar desafios vivenciados com a pesquisa “Avaliação Institucional na Educação Infantil: percursos formativos”, vinculada aos estudos do Grupo de Pesquisa Formação e Atuação de Educadores - GRUFAE5 . Situada no campo da Educação Infantil (EI) ${ }^{6}$, essa pesquisa focaliza as ressonâncias da avaliação institucional nos processos de formação continuada docente. Busca compreender as relações que se constituem entre a avaliação institucional na primeira etapa da Educação Básica e os diferentes percursos de formação continuada vivenciados por docentes atuantes num dos 46 Centros Municipais de Educação Infantil (CMEI) que participaram do processo avaliativo realizado no ano de 2012, em Vitória - Espírito Santo (ES). Ancorada em referenciais teórico-metodológicos bakhtinianos (BAKHTIN, 2009, 2010, 2011), a pesquisa articula-se à opção metodológica de

\footnotetext{
${ }^{4}$ Ancorados no conceito de alteridade (BAKHTIN, 2011) e concebendo a pesquisa como processo construído coletivamente entre os diferentes sujeitos envolvidos, optamos por utilizar os verbos na $1^{\text {a }}$ pessoa do plural.

${ }^{5}$ O GRUFAE, constituído desde 2006, vincula-se à Linha de Pesquisa Docência, Currículo e Processos Culturais do Programa de Pós-Graduação em Educação (PPGE), do Centro de Educação (CE) da Universidade Federal do Espírito Santo (UFES). Ver também CÔCO et al., (2014).

${ }^{6}$ Desde a promulgação da LDB n. ${ }^{\circ}$ 9394/1996, o termo "Educação Infantil”" é utilizado para se referir às instituições educativas destinadas às crianças de 0 a 6 anos. No entanto, com a aprovação da Lei n. ${ }^{\circ} 11.114$, de 2005, que tornou obrigatório o início do ensino fundamental aos 6 anos de idade, a Educação Infantil passou a atender a faixa etária de 0 a 5 anos. Neste texto, faremos referência à faixa etária de 0 a 6 anos, tendo em vista que, na Educação Infantil, em razão de data de corte etário, também são atendidas crianças de 6 anos.
} 
abordagem qualitativa e de caráter exploratório, com procedimentos de análise documental e entrevistas semiestruturadas.

Reconhecendo o compromisso da pesquisa em articular-se à complexidade do contexto social, político e histórico, realçamos a relevância da constituição do quadro teóricometodológico na orientação da investigação a que nos propomos no campo da educação. Nesse sentido, as reflexões que desenvolvemos neste artigo vinculam-se às concepções de responsividade, excedente de visão, alteridade e relações dialógicas (BAKHTIN, 2009, 2010, 2011) destacando-se suas imbricações no delineamento da pesquisa em relação à definição dos sujeitos e dos lócus de investigação, assim como dos instrumentos e procedimentos de produção e de análise de dados.

$\mathrm{Na}$ arquitetônica desse artigo, sistematizamos as discussões em quatro movimentos que, embora estejam organizados em tópicos, não se configuram como momentos estanques, e sim como situações vivenciadas em simultaneidade ao desenvolvermos a pesquisa, as quais nos convocam a diferentes escolhas. Sendo assim, inicialmente, após essa introdução, abordamos os princípios éticos, demarcando o compromisso do pesquisador com os sujeitos participantes da pesquisa numa relação de alteridade. Em seguida, compartilhamos o processo de delineamento do lócus de pesquisa e dos sujeitos participantes, realçando a importância de definirmos critérios com margens alargadas para acolher outros delineamentos quando necessário. Na sequência, focalizamos os procedimentos da análise documental discorrendo sobre o processo de produção de dados e os elementos que orientam sua análise. No quarto movimento, discutimos sobre o procedimento das entrevistas semiestruturadas em suas especificidades quanto à organização para produção dos dados e à definição dos elementos orientadores da etapa analítica. Finalizando as discussões, destacamos nossas considerações acerca dos desafios teórico-metodológicos em pesquisa educacional, enfatizando as contribuições da perspectiva teórico-metodológica bakhtiniana ao percurso vivenciado.

\section{PRINCÍPIOS ÉTICOS CIRCULANTES NA DINÂMICA DA PESQUISA}

Como pesquisadores, entendemos que uma atuação que se fundamenta em princípios éticos requer, primeiramente, que busquemos fortalecer nossa compreensão dos sentidos que imprimimos a essa questão e, sobretudo, como a traduzimos em nossos posicionamentos diante dos sujeitos de pesquisa, uma vez que 
[...] embora toda ética seja universal do ponto de vista da sociedade que a institui (universal porque seus valores são obrigatórios para todos os seus membros), está em relação com o tempo e a História, transformando-se para responder a exigências novas da sociedade e da Cultura, pois somos seres históricos e culturais e nossa ação se desenrola no tempo. (CHAUÍ, 2000, p. 435).

Na perspectiva da legislação brasileira, as questões relacionadas à ética em pesquisas com seres humanos são principalmente orientadas pela Resolução 466/12, por meio das Diretrizes e Normas Regulamentadoras de Pesquisas Envolvendo Seres Humanos (que revogou as Resoluções 196/96, 303/2000 e 404/2008) do Conselho Nacional de Saúde (CNS). Essa resolução toma por princípio o respeito à dignidade, à liberdade e à autonomia do ser humano que embasa as determinações da Comissão Nacional de Ética em Pesquisa (CONEP) e dos Comitês de Ética em Pesquisa (CEP) ${ }^{7}$.

Nesse âmbito, as diretrizes e normas que regulamentam pesquisas envolvendo seres humanos determinam procedimentos e concepções relacionados a termos, definições e responsabilidades do pesquisador ${ }^{8}$, atribuições do CONEP e dos CEP, protocolo de pesquisa, aspectos éticos e processo de consentimento livre e esclarecido. Consideramos importante a observância de que há controvérsias acerca dos sentidos que se compõem com base na ética institucionalizada e incorporada a um comitê, sendo elaboradas diversas críticas a esse modelo de organização vinculado à legislação ${ }^{9}$. Tais reflexões aqui apresentadas são importantes em respeito às palavras outras que abordam as questões éticas em diferentes perspectivas.

Entretanto, na ancoragem teórico-metodológica desta pesquisa, é em Bakhtin (2010) que encontramos uma expressão que nos torna responsáveis por cada ato singular de nossa vida e nos ampara na fundamentação ética da pesquisa em Ciências Humanas, já que “[...] eu ocupo no existir singular um lugar único, irrepetível, insubstituível e impenetrável da parte de um outro. [...] Tudo que pode ser feito por $\operatorname{mim}^{10}$ não poderá nunca ser feito por ninguém mais, nunca" (BAKHTIN, 2010, p. 96). Tais assertivas nos ajudam a refletir sobre as distintas posições de pesquisador e pesquisado, cada um em sua condição única, singular (BAKHTIN,

\footnotetext{
7 Previsto na Resolução n. ${ }^{\circ}$ 466/2012, do Conselho Nacional de Saúde (CNS). Disponível em: http://conselho.saude.gov.br/resolucoes/2012/Reso466.pdf. Acesso em: 8 jun. 2014.

${ }^{8}$ Em cumprimento às normas do CEP/CONEP, esclarecemos que a referida pesquisa foi submetida à análise dos órgãos responsáveis por meio de cadastro na Plataforma Brasil, sendo aprovada em 11/12/2014.

${ }^{9}$ Sobre esse posicionamento, ver Silveira e Hüning, 2010.

${ }^{10}$ Mantemos, em algumas partes do texto, a referência a primeira pessoa do singular como na obra do autor, realçando a condição singular de cada um de nós no ato responsivo diante do outro.
} 
2010), mesmo que enredados no processo dialógico em que cada ação se concretiza em resposta ao outro, cada enunciado se constitui mediante tantos outros já assimilados (BAKHTIN, 2011).

Em referência a essas reflexões, Faraco (2011) argumenta que a ética em Bakhtin é baseada no princípio tanto do sujeito moral sobre as normas quanto da alteridade sobre a individualidade. $\mathrm{O}$ autor afirma que o ato responsável tem como base o meu existir único. E esclarece que "É no excedente de visão - em seu sentido, pressupostos e consequências - que vamos encontrar o chão comum para a estética e a ética em Bakhtin" (FARACO, 2011, p. 24).

Tal dinâmica evidencia que, quando nos dispomos a entrar em empatia com o outro, lançamo-nos ao encontro dialógico em que nos constituímos como sujeitos e assumimos uma atitude responsiva nessa relação (BAKHTIN, 2010). Trata-se de um processo constitutivo que convoca cada um como ser insubstituível e no qual o ponto de vista do outro possibilita completar a percepção de mim mesmo, uma vez que, do meu lugar, não consigo ver-me inteiramente, precisando do excedente de visão do outro, pois:

O excedente da minha visão em relação ao outro indivíduo condiciona certa esfera do meu ativismo exclusivo, isto é, um conjunto daquelas ações internas ou externas que só eu posso praticar em relação ao outro, a quem elas são inacessíveis no lugar que ele ocupa fora de mim; tais ações completam o outro justamente naqueles elementos em que ele não pode completar-se (BAKHTIN, 2011, p. 22-23).

Envolvidos como pesquisadores nessa cadeia dialógica, nossa interlocução se efetiva por meio das palavras dos sujeitos participantes e também através dos enunciados presentes nos textos de documentos que integraram o conjunto dos dados da pesquisa. Sendo assim, nesses distintos momentos de "[...] produção de conhecimento no âmbito das ciências humanas, o que se coloca em destaque é o compromisso ético de construir o sólido entendimento humano da experiência vivida" (SOUZA; ALBUQUERQUE, 2012, p. 116).

Desse modo, compreendemos que o excedente de visão implica essa dimensão ética, pois, ao buscar situar-me no lugar do outro, comprometo-me responsivamente em contribuir com algo que somente eu, do lugar que ocupo, posso ver. Nesse sentido, cabe ao pesquisador a responsabilidade em definir, como parte dos encaminhamentos metodológicos da pesquisa, os lócus e os sujeitos participantes, mantendo-se aberto aos distintos pontos de vista que podem ajudar a complementar seu horizonte.

\section{DELINEAMENTO DOS SUJEITOS PARTICIPANTES E DOS LÓCUS DE}




\section{PESQUISA}

No intuito de seguirmos ao encontro de enunciados que dialogassem com as questões elencadas para a pesquisa, articulamos os procedimentos metodológicos ao seu objetivo geral de compreender as ressonâncias da avaliação institucional na EI nos processos de formação continuada. Numa aproximação aos objetivos específicos, no propósito de contextualizar a avaliação institucional na EI no cenário das políticas públicas educacionais atuais, definimos a análise documental como procedimento para a produção desses dados. Já a opção pelo procedimento de entrevistas semiestruturadas se articulou aos outros dois objetivos específicos que visavam analisar as diferentes etapas do processo de avaliação institucional e explorar os processos de formação continuada vivenciados pelos docentes. Nesse quadro, assinalamos que cada procedimento teve um sentido próprio com singularidades que se materializaram na elaboração de roteiros diferenciados para a análise documental e a realização de entrevistas.

Focalizando os sujeitos da pesquisa, consideramos os docentes que atuavam mais diretamente com as crianças, ou seja, professores, pedagogos, assistentes ${ }^{11}$ de EI e o diretor. Para a definição da instituição em que realizamos as entrevistas com os sujeitos, optamos pelo levantamento inicial de dados junto à Secretaria Municipal de Educação (SEME), por meio da Gerência de Educação Infantil (GEI) e da Assessoria Técnica de Estatística e Planejamento (ATP). Esse levantamento inicial se justificou pela abrangência dos possíveis lócus da pesquisa, visto que, no total, foram 46 instituições de EI que participaram, em 2012, da avaliação institucional na EI no município onde desenvolvemos a pesquisa. Com o intuito de reduzirmos esse quantitativo e acessarmos, no máximo, seis, das 46 instituições que participaram do processo avaliativo, buscamos aquelas que atendessem a maior parte dos seguintes critérios:

a) Atendimento às crianças de 0 a 6 anos.

b) Permanência de, no mínimo, 60\% dos profissionais docentes no CMEI (professores, pedagogos, assistentes de EI e diretor), com base no ano de 2012 em comparação com o de 2014.

c) Elaboração do Projeto Político-Pedagógico (PPP), já que esse é um dos documentos que compõem o conjunto de fontes para a análise documental.

d) Participação das famílias no processo avaliativo empreendido, pois, apesar de as famílias não serem sujeitos de nossa pesquisa, reconhecemos a importância de sua

\footnotetext{
${ }^{11}$ Refere-se a um conjunto de profissionais que atuam em funções de apoio ao trabalho pedagógico, em especial ao trabalho docente, nas instituições de educação infantil (CÔCO, 2010). Ver também Côco e Paulino (2016).
} 
participação no sentido de contribuir com a análise da qualidade da EI ofertada às crianças (para esse cálculo, foi realizada uma comparação proporcional entre o total de participantes de cada unidade e o de crianças, com base em dados disponíveis na GEI).

e) Documentação do processo avaliativo por meio de diferentes formas de registro (atas, fotos, filmagens). Para a priorização das unidades que poderiam ser pesquisadas, consideramos o nível de detalhamento nos registros escritos e a permanência na instituição de algum responsável pelos registros.

f) Desenvolvimento de ações com base nos resultados da avaliação institucional, pois, nesse caso, temos mais elementos acerca das ressonâncias da avaliação institucional nos processos formativos docentes.

Ao concluirmos esse levantamento de dados, encontramos 25 instituições que atendiam crianças de 0 a 6 anos (relativo ao critério "a"). Dessas 25, evidenciamos que oito instituições de EI permaneciam com mais da metade dos mesmos profissionais da equipe docente que participaram da avaliação institucional em 2012 (referente ao critério "b”) e que 100\% desse total tinham o PPP elaborado (relativo ao critério "c").

Quanto à participação das famílias, constatamos que o índice foi abaixo de $20 \%$ em cada uma das oito instituições (referente ao critério "d"), não havendo, portanto, diferenças significativas que determinassem a definição das seis instituições pretendidas, o que nos levou a não prosseguir o levantamento com base nesse critério. Desse modo, mantivemos o quantitativo de oito instituições de EI para a próxima etapa e, no caso de aceite de mais de uma instituição, definiríamos nosso lócus de pesquisa, se necessário, retomando os critérios estabelecidos. Ressaltamos que inicialmente perspectivamos a realização da pesquisa em apenas uma instituição de EI.

Cientes desse princípio quanto aos critérios "e" e "f", nossa expectativa foi buscar, durante os contatos, entre as oito instituições selecionadas, aquela que mais se aproximasse desses parâmetros. Entretanto, antes de iniciarmos esses contatos, desconsideramos duas instituições, em razão de não atenderem aos critérios "e" e "f", mantendo então, seis instituições como possíveis lócus de desenvolvimento da pesquisa. Afinal, ocupando um posicionamento singular como pesquisadores, reconhecemos que os critérios nos orientam, mas não podem determinar os rumos da pesquisa sem a nossa tomada de posição, uma vez que: 
vista abstrato cognitivo carece de um enfoque axiológico, a diretriz axiológica necessita de que ocupemos uma posição singular no acontecimento único da existência, de que nos encarnemos. Todo juízo de valor é sempre uma tomada de posição individual na existência [...]. (BAKHTIN, 2011, p. 117).

Definido então nosso conjunto de instituições, iniciamos, em setembro de 2014, os contatos por telefone com os seis CMEI para apresentar nosso propósito de pesquisa e agendar um encontro com a direção das instituições que se interessassem em participar, disponibilizando-nos a compartilhar o projeto também com os demais profissionais. Na semana seguinte, tivemos a confirmação de aceite de uma instituição e agendamos o primeiro encontro, no qual elaboramos um cronograma iniciando com a análise documental (PPP e PA) e a seguir com os agendamentos das entrevistas. Desenvolvemos esses procedimentos de produção de dados entre novembro e dezembro de 2014. No desenvolvimento inicial da pesquisa, constatamos que essa instituição não atendia crianças de 0 a 3 anos e as assistentes de EI não haviam participado da avaliação institucional em 2012. Portanto, não seria possível contar com suas vozes sobre o processo de avaliação institucional em interlocução com a formação continuada.

Ao compreendermos a importância do diálogo com as assistentes de EI, retomamos os contatos telefônicos com as seis instituições anteriormente selecionadas de forma aleatória e uma delas mostrou-se disposta a participar da pesquisa. Retornamos à instituição em março de 2015, quando organizamos as datas de realização da análise documental e das entrevistas, desenvolvendo esses dois procedimentos entre março e abril desse mesmo ano. Numa visão panorâmica dos procedimentos metodológicos da pesquisa, seu desenvolvimento se articula em dois movimentos. Um primeiro movimento compõe-se pela análise documental que envolve dois grupos de documentos e, um segundo movimento se constitui pela realização de entrevistas semiestruturadas, incluindo duas instituições de EI e 11 docentes, sendo duas assistentes de EI, duas diretoras, três pedagogas e quatro professoras ${ }^{12}$. Assentes nesse desenho metodológico, abordamos a seguir nossa interlocução com os documentos.

\section{ANÁLISE DOCUMENTAL: APROXIMAÇÕES AO CONTEXTO DOS SUJEITOS}

\footnotetext{
${ }^{12}$ Adotamos, textualmente, a referência ao gênero feminino e a mantemos ao longo do texto, embora um dos participantes seja do sexo masculino, no sentido de preservar a identidade desse docente e também de demarcar a condição de maioria feminina no campo da EI no ES e no Brasil.
} 
Considerando os documentos como produção textual e concebendo os textos como possibilidades de contato dialógico com o contexto, enfatizamos que, na análise documental, são considerados documentos "[...] quaisquer materiais escritos que possam ser usados como fonte de informação sobre o comportamento humano" (PHILLIPS, apud LÜDKE; ANDRÉ, 1986, p. 38).

Focalizando os lócus da pesquisa, inicialmente pretendíamos realizar o procedimento de análise documental exclusivamente com base em documentos relacionados ao município pesquisado, por meio da Lei n. ${ }^{\circ}$ 8.051/10 que instituiu o Sistema de Avaliação da Educação Municipal Pública de Vitória (VITÓRIA, 2010) e dos Indicadores de Qualidade da Educação Pública de Vitória-ES (VITÓRIA, 2012), bem como a partir de documentos próprios da instituição de EI como o Projeto Político-Pedagógico (PPP) e o Plano de Ação (PA).

No decorrer de nossos estudos, encontramos, na abordagem do ciclo de políticas ${ }^{13}$ de Stephen Ball (2001, 2009), um importante aporte teórico para a contextualização da avaliação institucional e da formação continuada na EI no cenário das políticas públicas. Essa abordagem constitui método que contribui para o entendimento de como são elaboradas as políticas, direcionando-nos para a redefinição das fontes documentais e apoiando nossas análises na perspectiva bakhtiniana dos sentidos de texto e contexto.

Sendo assim, ampliamos o conjunto de documentos, incluindo outros que, em nossa compreensão, integram o que Ball $(2001,2009)$ denomina como contexto de produção de textos, relacionado à definição de políticas públicas. Diante da variada produção de documentos oficiais no contexto da primeira etapa da educação básica, consideramos, como critérios para definir os documentos atinentes ao contexto de produção de textos, constituindo o primeiro ${ }^{14}$ grupo, sua implicação no campo da EI em diálogo com a avaliação institucional e com questões circundantes à nossa pesquisa, quais sejam a formação, a qualidade e os direitos das crianças. Nesse processo, também redirecionamos o acesso a alguns documentos para compor o que o autor considera como contexto das práticas, caracterizado pela efetivação das políticas,

\footnotetext{
${ }_{13}$ Partimos da abordagem formulada por Ball $(2001,2009)$ e disseminada por outros pesquisadores como Mainardes (2006) sobre o ciclo de políticas que considera os contextos de influência, de produção de texto e das práticas para compreender a elaboração dessas políticas.

${ }^{14}$ Situam-se nesse primeiro grupo documentos que se relacionam ao contexto de produção de textos de acordo com a abordagem do ciclo de políticas de Ball $(2001,2009)$. Esse conjunto de textos é composto dos seguintes documentos: Critérios para um atendimento em creches que respeite os direitos fundamentais das crianças (BRASIL, 1995); Indicadores da Qualidade na Educação Infantil (BRASIL, 2009); Educação Infantil: Subsídios para a Construção de uma Sistemática de Avaliação (BRASIL, 2012); e a lei que regulamenta o SAEMV (VITÓRIA, 2010).
} 
solicitando o PPP e o PA na própria instituição, compondo o segundo ${ }^{15}$ grupo.

Nesse sentido de diálogo com os documentos, para a etapa de produção dos dados, elaboramos planilhas organizativas, possibilitando mapear as informações constantes na documentação definida para esse momento da pesquisa. Nessas planilhas, registramos a identificação do documento e as respectivas informações sobre data e origem, autores ou responsáveis pela elaboração/aprovação, bases argumentativas, objetivos, interlocutores e concepções evidenciadas. Esse registro possibilitou uma visão conjunta dos textos mapeados com suas interlocuções, discordâncias e complementaridades, na perspectiva da expressão de concepções e ideias ou indicação de propostas atinentes à avaliação institucional na EI e à formação continuada. Na sequência, após os registros, os documentos foram igualmente catalogados e classificados nos dois grupos já mencionados anteriormente.

Para a análise dos dados produzidos com os documentos do primeiro grupo, investimos num diálogo na perspectiva de relações dialógicas entre os enunciados dos próprios documentos, explorando elementos que nos subsidiassem na compreensão do cenário das políticas educacionais em que se inserem atualmente a avaliação institucional na EI e a formação continuada. Em relação à análise dos dados produzidos com os documentos do segundo grupo, nossos investimentos se direcionaram a um diálogo de suas relações dialógicas com os enunciados das docentes entrevistadas, explorando elementos que nos subsidiassem na análise das etapas que integram o evento da avaliação institucional na EI e suas ressonâncias na formação continuada. Ampliando essa possibilidade de análise, consideramos importante o diálogo com as docentes que vivenciaram o processo avaliativo na expectativa de interagir com seus enunciados por meio da realização de entrevistas individuais semiestruturadas.

\section{ENTREVISTAS SEMIESTRUTURADAS: ENCONTROS DIALÓGICOS COMAS DOCENTES}

No que concerne às nossas concepções acerca da constituição dos sujeitos, defendemos que a formação como seres humanos está inevitavelmente ligada ao convívio com o outro, nos constituindo como sujeitos através da linguagem e das relações que vivenciamos no contexto social e histórico (BAKHTIN, 2011). Assim, a interlocução com as docentes - professoras,

\footnotetext{
${ }^{15}$ Nesse grupo incluem-se os documentos que se relacionam ao contexto das práticas, sendo eles: Indicadores da Qualidade na Educação Infantil Pública de Vitória (VITÓRIA, 2012); PPP e PA dos dois CMEI onde realizamos a pesquisa, e foram analisados em dialogia com os enunciados expressos pelas participantes nas entrevistas.
} 
diretora, assistentes de Educação Infantil e pedagogas -, por meio das entrevistas, nos possibilitou conhecer os processos de formação continuada vivenciados por elas e dialogar sobre seus pontos de vista a respeito das diferentes etapas da avaliação institucional.

Durante a realização desse procedimento, nos colocamos em diálogo com os sujeitos que se dispuseram a participar da pesquisa numa perspectiva de formação recíproca, constituindo cada encontro como espaço dialógico e momento de interlocução entre pesquisador e pesquisado, sem abdicar da atitude responsiva que mencionamos no início deste texto e que nos cabe pela condução ética da pesquisa. Reafirmamos que, como esse procedimento foi subsequente à análise documental, estávamos um pouco mais familiarizados com o contexto dos CMEI em que desenvolvemos nosso estudo, o que contribuiu para o seu planejamento, possibilitando o contato de nossos enunciados com outros que nos antecederam, pois somos simultaneamente ouvintes e falantes e "[...] cada enunciado é um elo na corrente complexamente organizada de outros enunciados" (BAKHTIN, 2011, p. 272).

Tomando como ponto de partida as abordagens de Rocha, Daher e Sant'anna (2004), que reconhecem a complexidade da entrevista, concebendo-a como dispositivo de produção de texto numa perspectiva social e histórica, realizamos algumas articulações no que concerne ao seu planejamento e à sua realização. Quanto ao momento de preparação, levamos em consideração o problema de estudo e os objetivos estabelecidos em articulação com nosso conhecimento acerca dos sujeitos e das instituições de EI, para elencarmos os objetivos próprios da entrevista e revisarmos o roteiro. Os instrumentos foram configurados conforme as categorias elencadas, pré-testados e ajustados em função das necessidades indicadas nas testagens. Cabe ressaltar que a entrevista tem objetivos específicos correlacionados com os propósitos do estudo, porém não os mesmos, pois transferir para a entrevista a expectativa de alcançar os objetivos da pesquisa equivale a promover um "deslocamento da palavra do entrevistado, que passa a ocupar o espaço daquele que fornece respostas às perguntas da pesquisa (lugar que, obviamente, deveria ser ocupado pelo pesquisador)" (ROCHA; DAHER; SANT'ANNA, 2004, s/p). Nessa perspectiva, buscamos adentrar nossos lócus de pesquisa e nos aproximar dos sujeitos envolvidos com um planejamento básico de trabalho que se mantivesse aberto a outras possibilidades de organização. Tais alterações poderiam ocorrer conforme os encadeamentos das ações na dinâmica interativa que caracteriza o processo de pesquisa.

Assim, acreditamos que o sujeito "[...] não pode ser percebido e estudado como coisa porque, como sujeito e permanecendo sujeito, não pode tornar-se mudo; consequentemente o 
conhecimento que se tem dele só pode ser dialógico" (BAKHTIN, 2011, p. 400, grifo do autor). Assentes nessa premissa de perceber o sujeito em sua condição dialógica, optamos por trabalhar na pesquisa com quem se dispusesse ao encontro, assinalando que a concordância do coletivo dos CMEI em realizarmos a pesquisa não exigia que todos os sujeitos dela participassem diretamente. Ainda esclarecemos que as entrevistas foram individuais com sete docentes e em duplas com quatro docentes. Essa alteração na proposta inicial de entrevista individual foi sugerida pelas docentes com argumentações baseadas na grande disposição para a participação numa conversa em dupla e na pouca disponibilidade de tempo devido à intensidade de trabalho no CMEI.

As entrevistas aconteceram entre dezembro de 2014 e abril de 2015, sendo realizadas em datas previamente agendadas de acordo com as condições objetivas de cada CMEI. Assim, nossos encontros foram intercalados com importantes eventos do cotidiano da EI como a eleição para diretores, a organização de visitas pedagógicas com as turmas aos espaços do município, reuniões e encontros de formação na SEME com pedagogos e/ou diretores, assembleias dos professores, reuniões e encontros com as famílias, entre outros.

Como nos inserimos nessa movimentada dinâmica da instituição de EI, os registros em áudio das entrevistas, que totalizaram 5h20min, evidenciaram a dimensão de simultaneidade em que diversas ações se desenvolvem. Em alguns momentos, ouvimos músicas cantadas com as crianças de uma das turmas dos CMEI, crianças que chegam à sala e conversam conosco, familiares que buscam informação, reunião com os membros do conselho de escola, entre outras situações que compõem o dia a dia das instituições de EI. No contexto social mais amplo, as greves de motoristas de ônibus, manifestações e protestos contra a corrupção e impunidade no país, também compõem nossa trajetória de produção de dados, pois, em algumas vezes, foi necessário o reagendamento dos encontros em razão dessas mobilizações.

Cabe assinalar que, ao conduzirmos as entrevistas em consonância com o percurso enunciativo de cada participante, em alguns momentos, com apenas uma pergunta, inúmeras questões emergiam no encadeamento das ideias e enunciados compartilhados, contemplando e inserindo outros itens no roteiro. Na sequência do procedimento, as entrevistas foram transcritas na ordem exata das falas, tanto da pesquisadora como das docentes, com a identificação de cada CMEI, a data, os nomes e as funções de cada docente, produzindo cerca de 80 páginas de texto. E na continuidade do trabalho, para a etapa de organização dos dados produzidos, em respeito ao princípio ético de confidencialidade da identidade dos sujeitos entrevistados, definimos codificações para cada docente. Essa etapa se apresentou com diferentes alternativas sobre 
como reuniríamos esses enunciados, considerando que as 11 docentes participantes atuavam em dois CMEI diferentes e que a sistematização dos dados precisa dialogar com as premissas teórico-metodológicas definidas e ainda tem importante desdobramento no processo analítico.

Entre inúmeras possibilidades, aproximamo-nos inicialmente da ideia de uma grande arena polifônica e carnavalesca (BAKHTIN, 2013), envolvendo todas as docentes sem preocupação com critérios estabelecidos previamente a partir de sua função, instituição, formação ou outro atributo que representasse critério hierárquico, temporal ou geográfico. Mas faltaria uma condição indispensável que, segundo BAKHTIN (2013), caracteriza essa expressão da cultura cômica popular na obra de Rabelais: o contato direto, físico, sinestésico entre os participantes, o sentimento de estar junto, pois, nesse encontro carnavalesco, “[...] Ao mesmo tempo, o povo sente a sua unidade e sua comunidade concretas, sensíveis, materiais e corporais" (BAKHTIN, 2013, p. 222).

Assim, inspiramo-nos no conceito de singularidade e na condição irrepetível de cada vivência (BAKHTIN, 2010) e definimos uma nomeação codificada das docentes de acordo com suas diferentes atuações, atribuindo como identificação letras em ordem alfabética para cada função, correspondente à ordem temporal inversa de realização das entrevistas. Quanto à questão de que as docentes atuavam em instituições diferentes, nossa opção foi reuni-las num só grupo, sem localizar cada CMEI. Essa decisão se justifica, tanto pela confidencialidade de suas identificações quanto pela compreensão do princípio de que as relações dialógicas se materializam entre sujeitos distantes no tempo e no espaço, desde que conservem algum ponto de contato entre si (BAKHTIN, 2011). Nesse sentido, acreditamos que, entre as docentes dos dois CMEI onde realizamos parte da produção dos dados da pesquisa, as vivências de um processo de avaliação institucional se configuram como um ponto de contato entre elas.

\section{CONSIDERAÇÕES EM MOVIMENTO}

Neste texto, compartilhamos desafios metodológicos vivenciados com o desenvolvimento de uma pesquisa e ressaltamos as contribuições da perspectiva bakhtiniana como base teórico-metodológica para as tomadas de decisão diante de diferentes tensões e demandas que emergiram no desenvolvimento desse trabalho acadêmico. Assinalamos nossa busca por vivenciar seus intensos movimentos na perspectiva das relações dialógicas e, entre argumentações, questionamentos e variadas possibilidades, nossas opções metodológicas não 
apenas direcionaram a composição do estudo, como promoveram diferentes processos de assimilação.

Desse modo, em uma perspectiva desse processo de assimilação, os pressupostos teóricometodológicos bakhtinianos apoiaram o percurso da pesquisa em direção ao objetivo geral de compreender as ressonâncias da avaliação institucional nos processos de formação continuada docente na EI. Em outra perspectiva, constituíram suporte formativo para as próprias questões metodológicas e seus entrelaçamentos com as diferentes etapas da pesquisa.

Nesse sentido, realçamos que nosso percurso teórico-metodológico não se limitou à definição de procedimentos para produção de dados, pois envolveu uma articulação constante entre os objetivos da pesquisa, as condições objetivas do pesquisador, o contexto dos sujeitos participantes, o acompanhamento de estudos e pesquisas em desenvolvimento na área temática investigada e o planejamento das formas de registro, organização e sistematização dos dados.

Considerando o conceito de responsividade, compreendemos que cabe ao pesquisador planejar, prever, delinear o percurso metodológico da pesquisa que se propõe a desenvolver. Entretanto, como movimento vivo constituído nas relações entre o pesquisador e os sujeitos participantes, esse caminho exige sensibilidade para perceber a necessidade de alterações e, mantendo o foco nos objetivos da pesquisa, revermos procedimentos e decisões.

Nesse direcionamento, acreditamos que a participação de outra instituição de EI na realização da pesquisa, embora diferente do que havia sido inicialmente planejado, foi extremamente relevante por abarcar mais de um contexto, contando com o excedente de visão de outros sujeitos, compondo uma polifonia que nos enriquece com variados pontos de vista sobre a interlocução da avaliação institucional com a formação continuada na EI.

Compondo a arquitetônica da pesquisa, acreditamos que as opções metodológicas ancoradas em referenciais bakhtinianos nos possibilitaram estabelecer conexões entre os elementos constituintes do estudo, pois a metodologia, antes de ser um capítulo obrigatório para compormos a pesquisa, nos convocou a um posicionamento político e ético, inspirado no conceito de alteridade como ato de repensar nossas concepções e compartilhar nossas aprendizagens. E ao compartilharmos essas múltiplas compreensões, desafiamo-nos a escapar da unidade em seu sentido monológico e a buscar contrapalavras, interagindo com o outro no sentido de propor, afirmar, refutar, silenciar, superar. Dispostos à continuidade desses encontros dialógicos, ressaltamos que as ideias aqui enunciadas permanecem em movimento e nos remetem ao percurso da pesquisa não no sentido do passado, e sim com expectativas de futuras dialogias. 


\section{REFERÊNCIAS}

BAKHTIN, Mikhail Mikhailovich. Estética da criação verbal. Tradução de Paulo Bezerra. 6. ed. São Paulo: Martins Fontes, 2011.

. Marxismo e filosofia da linguagem: problemas fundamentais do método sociológico da linguagem. Tradução de Michel Lhud e Yara Frateschi Vieira. 13. ed. São Paulo: Hucitec, 2009.

. Para uma filosofia do ato responsável. Tradução de Valdemir Miotello e Carlos Alberto Faraco. São Carlos: Pedro \& João, 2010.

. A cultura popular na Idade Média e no Renascimento: o contexto de Francois Rabelais. Tradução de Yara Frateschi Vieira. 8. ed. São Paulo: Hucitec, 2013.

BALL, Stephen Joseph. Diretrizes políticas globais e relações políticas locais em educação. Currículo sem Fronteiras, v. 1, n. 2, p. 99-116, 2001. Disponível em: http://www.curriculosemfronteiras.org/vol1iss2articles/ball.pdf. Acesso em: 23 ago. 2014.

Entrevista com Stephen Joseph Ball: um diálogo sobre justiça social, pesquisa e política educacional. Entrevista concedida a Mainardes, J. \& Marcondes, M. I. Educação e Sociedade, Campinas, v. 30, n. 106, p. 303-318, jan./abr. 2009.

BRASIL. Ministério da Educação/ SEF/ COEDI. Critérios para um atendimento em creches que respeite os direitos fundamentais das crianças. Brasília, 1995.

. Resolução $\mathrm{N}^{\circ}$ 466, de 12 de dezembro de 2012. Aprova diretrizes e normas regulamentadoras de pesquisas envolvendo seres humanos. Disponível em:

http://conselho.saude.gov.br/resolucoes/2012/Reso466.pdf. Acesso em: 08 jun. 2014.

Indicadores da qualidade na educação infantil. Brasília: MEC/SEB, 2009.

Disponível em: http://www.portal.mec.gov.br/dmdocuments/indic_educ_infantil.pdf. Acesso em: 5 maio 2013.

. Educação Infantil: subsídios para construção de uma sistemática de avaliação.

Brasília: MEC/SEB, 2012. Disponível em:

http://portal.mec.gov.br/index.php?option=com_docman\&view=download\&alias=11990-

educacao-infantil-sitematica-avaliacao-pdf\&Itemid=30192. Acesso em: 29 jun. 2013.

CHAUÍ, Marilena. Convite à filosofia. São Paulo: Ática, 2000. Disponível em: http://www.filosofia.seed.pr.gov.br/arquivos/File/classicos_da_filosofia/convite.pdf. Acesso em: 29 abr. 2013.

CÔCO, Valdete. Auxiliar de Educação Infantil. In: OLIVEIRA, D. A.; DUARTE, A. M. C.; VIEIRA, L. M. F. DICIONÁRIO: trabalho, profissão e condição docente. Belo Horizonte: UFMG/Faculdade de Educação, 2010a. Disponível em:

http://www.gestrado.net.br/pdf/51.pdf. Acesso em: 24 jun. 2013. 
A configuração do trabalho docente na educação infantil. In: CONGRESSO ÍBEROBRASILEIRO DE ADMINISTRAÇÃO DA EDUCAÇÃO, 1., 2010b. Anais eletrônicos...: ANPAE. Disponível em: http://www.anpae.org.br/iberolusobrasileiro2010/cdrom/118.pdf. Acesso em: 17 nov. 2013.

CÔCO, Valdete, et al. Grupo de Pesquisa Formação e Atuação de Educadores (GRUFAE). In: Seminário de Grupos de Pesquisa sobre Crianças e Infâncias (GRUPECI) Anais eletrônicos... Goiânia/GO, 2014. Disponível em: http://www.grupeci.fe.ufg.br/up/693/o/RE53.PDF. Acesso em: 18 nov. 2014.

FARACO, Carlos Alberto. Aspectos do pensamento estético de Bakhtin e seus pares. Letras de Hoje, Porto Alegre, v. 46, n. 1, p. 21-26, jan./mar. 2011. Disponível em:

www.scielo.br/scielo.php?script=sci_nlinks\&ref=000049\&pid.. Acesso em: 22 maio 2013.

LÜDKE, Menga; ANDRÉ, Marli Eliza Dalmaso Afonso. Pesquisa em educação: abordagens qualitativas. São Paulo: EPU, 1986.

MAINARDES, Jefferson. Abordagem do ciclo de políticas: uma contribuição para a análise de políticas educacionais. Educação e Sociedade, Campinas, v. 27, n. 94, p. 47-69, jan./abr. 2006. Disponível em: <http://www.cedes.unicamp.br>. Acesso em: 23 out. 2013. http://dx.doi.org/10.1590/S0101-73302006000100003 .

PAULINO, Verônica Belfi Roncetti; CÔCO, Valdete. Políticas públicas educacionais: vozes que emergem no trabalho docente na Educação Infantil. Ensaio: aval. pol. públ. Educ., Rio de Janeiro, v.24, n. 92, p. 697-718, jul./set. 2016. Disponível em: < http://www.scielo.br/pdf/ensaio/v24n92/1809-4465-ensaio-24-92-0697.pdf . Acesso em 25 nov. 2016. doi: 10.1590/S0104-40362016000300008 697

ROCHA, Décio; DAHER, Maria Del Carmen; SANT'ANNA, Vera Lúcia de Albuquerque. A entrevista em situação de pesquisa acadêmica: reflexões numa perspectiva discursiva. Revista Polifonia, Mato Grosso, v. 8, n. 8, p. s/p, 2004. Disponível em: http://cpd1.ufmt.br/meel/arquivos/artigos/24.pdf. Acesso em: 21 jul. 2013.

SILVEIRA, Ronie Alexsandro Teles da; HÜNING, Simone Maria. A tutela moral dos comitês de ética. Revista Psicologia \& Sociedade, v. 2, n. 22, p. 388-395, 2010. Disponível em: http://www.scielo.br/pdf/psoc/v22n2/20.pdf. Acesso em: 14 jun. 2014.

SOUZA, Solange Jobim; ALBUQUERQUE, Elaine Deccache Porto. A pesquisa em ciências humanas: uma leitura bakhtiniana. Bakhtiniana, São Paulo, 7 (2): 109-122, Jul./Dez. 2012. Disponível em: http://www.scielo.br/pdf/bak/v7n2/08.pdf. Acesso em 15 fev. 2013.

VITÓRIA. Lei n. $^{\circ}$ 8.051, de 22 de dezembro de 2010. Vitória, 2010. Disponível em: http://sistemas.vitoria.es.gov.br/webleis/consulta.cfm?id=171640. Acesso em: 26 nov. 2013.

VITÓRIA. Indicadores da Qualidade na Educação Infantil Pública de Vitória-ES: sistema de avaliação da educação pública de Vitória/Prefeitura de Vitória, Secretaria Municipal de Educação, 2012, Vitória, ES. 64 p. 
Data de aceite: $29 / 09 / 2017$

Revista Reflexão e Ação, Santa Cruz do Sul, v. 25, n. 3, p. 10-27, Set./Dez. 2017. http://online.unisc.br/seer/index.php/reflex/index 